\title{
Prolapsed urinary bladder haemangioma: a rare presentation
}

\begin{abstract}
Urinary bladder haemangiomas are rare benign mesenchymal tumors. They usually present with macroscopic haematuria. We report an unusual case of a 6 month old female child; she presented with a bleeding interlabial mass which turned out to be prolapsed urinary bladder haemangioma.
\end{abstract}

Keywords: Haemangioma; Prolapsed inter labial mass
Volume 6 Issue I - 2017

\author{
Khan Niyaz A, Jhanwar Praveen, Yadav Partap \\ S, Muffazzal Rassiwala, Pinaki R Debnath \\ Department of Pediatric Surgery, Lady Hardinge Medical \\ College \& Kalawati Saran Children's Hospital, India
}

\begin{abstract}
Correspondence: Praveen Jhanwar, Department of Pediatric Surgery, Room No 24,New Resident Block, Doctors Hostel, Lady Hardinge Medical College, New Delhi, India, Tel 9793286796, Email jhabbuu@gmail.com
\end{abstract}

Received: November 20, 2016 | Published: January 18, 2017

\section{Introduction}

Haemangiomas are the most common benign vascular tumors of childhood; they can occur at any anatomic site cervicofacial, thoracoabdominal region, extremities, including solid and hollow viscera. Genitourinary tract haemangiomas are however a very rare entity. The most common mode of presentation for genitourinary tract haemangiomas is macroscopic haematuria; other less common presentations include lower abdominal pain and urinary retention. A written valid consent is taken from the parents for reporting this case.

\section{Case report}

A six months old female patient, presented in the emergency department with a red fleshy actively bleeding introtial mass. She was resuscitated and required blood and fresh frozen plasma transfusions. Systemic examination revealed microcephaly, bilateral genu valgus deformity, local examination revealed, a $5 \mathrm{cms}$ x $3 \mathrm{cms}$ reddish partly gangrenous mass prolapsing through the urethra, the uretheral meatus was completely occluded with it and vaginal orifice was normal (Figure 1). Routine biochemical tests (Kidney Function Test) were normal; there was no evidence of coagulation abnormalities or urinary tract infection. Patent foramen ovale was detected on echocardiography. Ultrasonogram of the KUB region showed mild hydroureteronephrosis on the right side, urinary bladder was normal. Cystouretheroscopy showed the pedunculated mass to be arising in the region of trigone towards right side, right ureteric orifice could not be located, left ureteric orifice was normal and urinary bladder showed no other abnormality (Figure 2). A single prolapsed mass was resected cystoscopically, haemostasis achieved and no 8 Fr Foley's catheter was left indwelling for 2 days. Histopathology revealed tumor was composed of dilated vascular channels lined with endothelial cells suggesting cavernous haemangioma. She had an uneventful postoperative course, and the hydroureteronephrosis resolved on follow up.

\section{Discussion}

Hemangiomas are benign vascular tumors arising from embryonic stem cells of an angioblastic lineage. They are classified as cavernous, capillary or arteriovenous. ${ }^{1}$ Urinary bladder hemangiomas are very rare and account for $0.6 \%$ of all bladder tumors. ${ }^{2}$ Cavernous bladder hemangiomas are most commonly solitary and usually located on bladder dome or ureterotrigonal region. They may also have co existent cutaneous haemangiomas or be associated with syndromes like Struge Weber, Proteus hence a detailed physical examination is a must. Isolated macroscopic haematuria is the usual presentation,but massive haematuria leading to shock has also been described.3 We report an unusual presentation of cavernous haemangioma of urinary bladder with per-uretheral prolapse and bleeding, presenting as an interlabial mass. There were no associated cutaneous or visceral haemangiomas.

The differential diagnosis of interlabial masses in pediatric age group includes uretheral prolapse, cysts of parauretheral glands, uretheral and vaginal fibroepithelial polyps, uretheral haemangiomas, malignant vaginal masses and prolapsed ureteroceles. Cavernous haemangiomas are mostly diagnosed during evaluation for gross haematuria. On radiological examination they appear as isoechoic polypoid intraluminal masses with mildly increased vascularity in the urinary bladder, usually there is no muscular involvement or perivesical extension. Hydroureteronephrosis may be present due to ureteral obstruction.

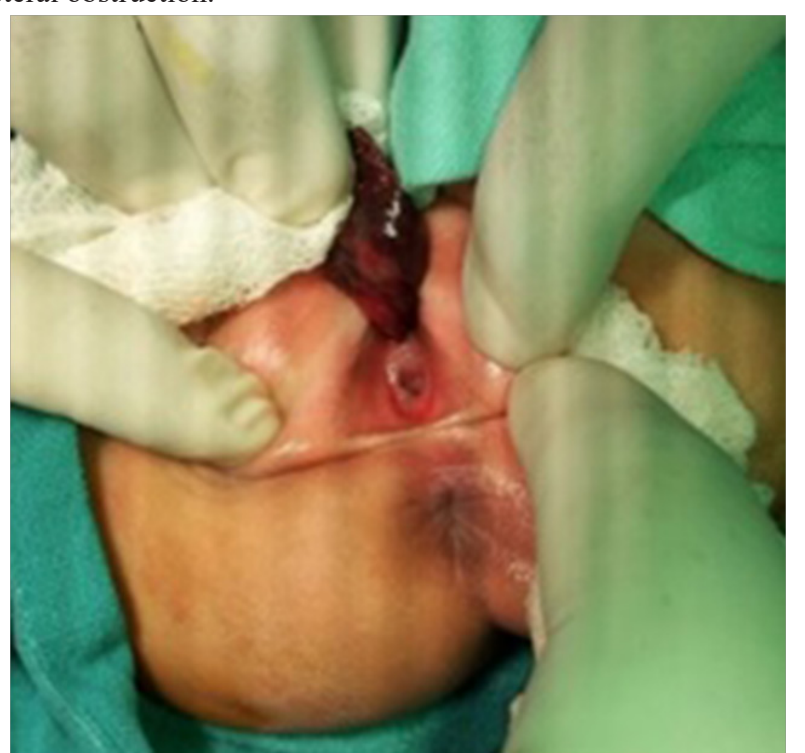

Figure I Clinical Picture Showing Mass Prolapsing Peruretherally With Normal Vaginal Opening. 


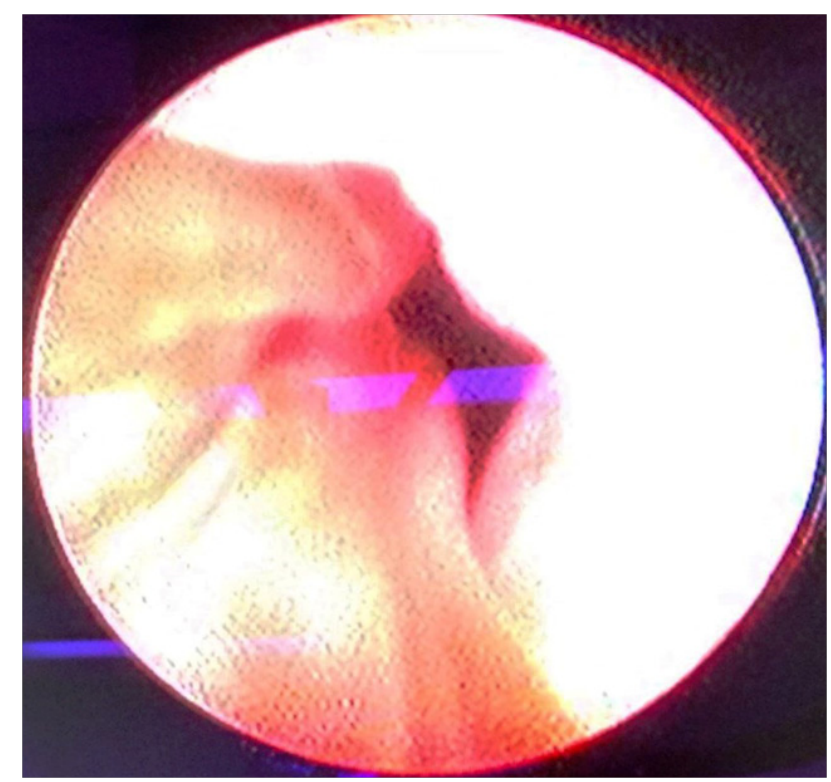

Figure 2 Cystoscopy Picture Demonstarting Pedical of Haemangioma In Urethra (Block arrow- Pedicle, line- bladder lumen).

Rhabdomyosarcoma is most common intraluminal bladder mass and the main differential and the diagnosis is confirmed histologically. Various treatment options are available, small lesions can be managed endoscopically with laser ablation (YAG) or coagulation. ${ }^{4,5}$ Large lesions require open surgical resection with partial cystectomy. ${ }^{6}$

In conclusion cavernous haemangiomas of urinary bladder are a rare cause of intravesical mass with hematuria in children and should be kept in differential diagnosis, more so if there is well defined margin and lack of muscle infiltration on radiological studies.

\section{Acknowledgements}

None.

\section{Conflict of interest}

The authors declare no conflict of interest.

\section{Funding}

None.

\section{References}

1. Cheng L, Nascimento AG, Neumann RM, et al. Hemangioma of the urinary bladder. Cancer. 1999;86(3):498-504.

2. Mor Y, Hitchcock JI, Zaidi SZ, et al. Bladder hemangioma as a cause of massive hematuria in a child. A case report and literature review. Scand J Urol Nephrol. 1997;31(3):305-307.

3. Numanoğlu KV, Tatli D. A rare cause of hemorrhagic shock in children:Bladder hemangioma. J Pediatr Surg. 2008;43(7):e1-e3.

4. Smith JA Jr. Laser treatment of bladder hemangioma. J Urol. 1990;143(2):282-284.

5. Kato M, Chiba Y, Saka K, et al. Endoscopic neodymium:yttrium aluminium garnet (Nd:YAG) laser irradiation of bladder hemangioma associated with Klippel-Weber syndrome. Int J Urol. 2000;7(4):145148 .

6. Ikeda T, Shimamoto K, Tanji N, et al. Cavernous hemangioma of the urinary bladder in an 8- year old child. Int J Urol. 2004;11(6):429-431. 